\title{
Gênero como possibilidade ou limite da ação social: um olhar sobre a perspectiva de crianças pequenas em um contexto de educação infantil
}

\author{
MÁRCIA BUSS-SIMÃO \\ Universidade Federal de Santa Catarina, \\ Florianópolis, SC, Brasil
}

\section{CONTEXTUALIZANDO O CAMPO PESQUISADO}

O presente texto é parte de uma pesquisa de doutorado já concluída e na qual a geração de dados ${ }^{1}$ foi realizada em 2009, durante nove meses, em uma instituição pública de educação infantil da rede municipal de Florianópolis/SC, localizada na zona urbana e que atende crianças de 0 a 6 anos de idade em período integral. A fim de elaborar uma descrição com base na perspectiva das crianças, utilizei procedimentos metodológicos provenientes da etnografia, lançando mão de registros escritos, fotográficos e filmicos.

$O$ grupo pesquisado contou com 15 crianças com idade entre 2 e 3 anos, sendo 12 meninas e 3 meninos. A maioria das crianças procedia de família nuclear, metade do grupo era filho único e a outra metade tinha um ou dois irmãos. A maior parte das crianças do grupo pesquisado enfrentava dificuldades em sua condição social e econômica.

1 Utilizo o termo geração de dados - e não coleta de dados - com base em Graue e Walsh (2003), que sinalizam o fato de que os dados não "andam por aî", esperando que algum investigador os recolha; ao contrário, eles provêm das relações e das interações complexas que o investigador estabelece com o campo investigado. 
No caso desta pesquisa, a realidade concreta para a qual dirigi o olhar diz respeito à estrutura social de uma instituição de educação infantil. Compreendo que essa estrutura social - instituição de educação infantil - é imposta pelos adultos, sendo portanto um contexto privilegiado para investigar como as crianças lidam com ela e como se manifestam corporalmente nas relações de poder com os adultos e com as outras crianças.

Com base em Ferreira (2002; 2004), concebo essa estrutura social adulta dotada de duas propriedades: primeiro como resultado de uma construção sócio-histórica que se destina à socialização das crianças; e, segundo, como resultado da presença do adulto/ professora, que se torna o elo que mantém, personifica e assegura que essa estrutura social funcione por meio dos arranjos espaciais e temporais na organização e planejamento do cotidiano para e com as crianças.

Embora o adulto/professora ocupe uma posição central nessa estrutura social, sua relevância neste estudo é, no entanto, periférica e relativamente indireta, pois não era pretensão deter-me em suas competências pedagógicas nem em suas concepções e pontos de vista em relação às crianças. O que interessa considerar neste estudo é que, dada essa ordem institucional adulta, ao participarem dessa estrutura por meio de ações sociais organizadas e regulares que permitem a sua reprodução no espaço e no tempo, as crianças passam a se integrar tanto na ordem institucional adulta como numa ordem emergente criada por elas: ordem social infantil instituinte ou emergente, como define Ferreira (idem).

Ao instituírem essa ordem social emergente, as crianças criam uma realidade alternativa à ordem institucional adulta, tendo como referência valores e regras sociais delas próprias, revelando que não se limitam a reproduzir o mundo dos adultos. Pelo contrário,

[...] o reconstroem e ressignificam através de múltiplas e complexas interações com os pares, permite mostrá-las não só como autoras de suas próprias infâncias, mas também como actores sociais com interesses e modos de pensar, agir e sentir específicos e comuns, capazes de gerar relações e conteúdos de relação, sentido de segurança e de comunidade que estão na sua gênese como grupo social. (Ferreira, 2004, p. 58)

Ao se objetivar olhar o cotidiano de uma instituição de educação infantil pela perspectiva das crianças, com a finalidade de compreender a emergência e a afirmação de uma ordem social emergente, é preciso deslocar o ângulo de análise de "cima para baixo",é preciso "[...] a identificação e análise da simultânea e recíproca construção social de três processos centrais: o da cultura das crianças, o da sua organização como grupo social de 'pares' e o da(s) sua(s) ordem(ns) sociai(s)" (idem, p. 58-59).

Ao se encontrarem regular e rotineiramente no mesmo contexto institucional e realizarem cotidianamente atividades conjuntas e ordenadas que satisfazem expectativas comuns e recíprocas, as crianças geram em suas práticas e relações uma ordem social emergente, a qual é socialmente convencionada por elas mesmas regulando e organizando as ações individuais e coletivas do grupo. 
Tais ações não fazem sentido fora de seu contexto, ou seja, não têm sentido isoladamente; elas só fazem sentido se interpretadas contextualmente. Elas só se tornam acontecimentos sociais se negociados e interpretados ou reinterpretados com os outros por meio de suas interações sociais. Identificar e compreender essa ordem social emergente tem sido também um desafio para pesquisadores, pois é preciso que se "mergulhe" nessa ordem social que é construída pelas crianças para que se possa legitimá-la e ser possível uma aproximação com suas perspectivas e com seus modos de socializar. Além disso, como afirma Danby (2005, p. 177, tradução minha): "Pelo reconhecimento das ordens sociais das crianças, as ordens sociais dos adultos também podem ser identificadas".

\section{GÊNERO COMO POSSIBILIDADE OU LIMITE DA AÇÃO SOCIAL}

Um dos objetivos da presente pesquisa consistia em investigar entre as crianças as formas, as significações e as vias de transmissão de elementos culturais e sociais que envolvem a dimensão corporal, assim como a emergência de novos elementos que reforçam, modificam, multiplicam, transformam, transgridem e transcendem ou simplesmente ocultam aqueles já estabelecidos. Dirigindo minha atenção às indicações dadas pelas crianças, identifiquei o gênero como sendo uma categoria central e constituidora de relações e possibilidades de ação social.

Além de essa categoria ser central para as crianças, o pertencimento e as noções de gênero envolvem uma variedade de conhecimentos e elementos sociais e culturais, os quais requerem um estudo minucioso para se compreender como e o que as crianças sabem e aprendem sobre esses elementos ao estabelecerem suas relações no cotidiano de uma instituição de educação infantil. Nesse sentido, tão importante como compreender o que as crianças sabem e aprendem sobre gênero, são os usos que elas dão a esse conhecimento nas relações que estabelecem com seus pares e também com os adultos.

No Brasil, os estudos sobre gênero têm crescido e avançado consideravelmente. Todavia, no âmbito da educação infantil são poucos os estudos que se detiveram nessa temática de pesquisa, entre os quais se destacam: Faria (2006); Felipe (1998; 2005; 2007; 2011); Finco (2004; 2010); Gobbi (1997); Rosemberg (1985; 1996; 2001); Sayão (2002; 2003; 2005), Silva e Luz (2010); no âmbito mais geral da educação, cabe ainda destacar a grande contribuição de Louro (1997; 1999; 2000; 2003; 2008a; 2008b).

A identificação de meninos e meninas por meio da categoria gênero, como um dado natural e biológico e como consequência da identificação da genitália, permeou durante muito tempo a compreensão dos estudos sobre essa temática. Apenas recentemente, no campo sociológico, a categoria gênero passou a ser compreendida como socialmente construída e produto de relações e ações sociais. No que se refere aos

2 Agradeço ao Deutscher Akademischer Austauschdienst (DAAD) pela bolsa de doutoramento que possibilitou a minha estada por um ano e quatro meses na Alemanha para aprofundamento dos estudos e acesso aos materiais em língua alemã e inglesa. 
estudos de gênero, a contribuição pioneria de Scott (1995), ao trazer o gênero como uma categoria útil para análise histórica, tem sido referência indispensável.

Outra denominação central para os estudos de gênero passou a ser o "doing gender" - "fazendo gênero"-, que primeiramente foi utilizada em um artigo científico pelos autores Candace West e Don H. Zimmerman, no ano de 1987, e também teve grande repercussão nos estudos do tema. No artigo, com base em uma compreensão sociológica, os autores definem gênero como uma realização de rotina, metódica e recorrente; e esse "fazer" gênero é realizado tanto por mulheres como homens, os quais, como membros da sociedade, passam a ser reféns de sua produção.

West e Zimmerman (1987) argumentam que o gênero não é um conjunto de traços, nem uma variável e nem um papel, mas o produto de ações sociais de algum tipo. O objetivo principal dos autores consiste em explorar como o gênero pode ser exibido ou retratado por meio da interação e, portanto, ser visto como "natural", quando na realidade ele é produzido. Thorne (1993, p.3, tradução minha) também é categórica em suas afirmações: "Em minhas observações, apoio plenamente a opinião de que o gênero é socialmente construído". Com base nessa prerrogativa, o gênero de uma pessoa não é simplesmente um aspecto do que se é, mas, mais especificamente, é algo que se faz, e se faz recorrentemente e em interação com os outros.

Os autores West e Zimmerman (1987) indicam que as consequências dessa compreensão têm grande importância, pois, quando se compreende o gênero como uma realização, como uma construção de uma propriedade, alcançada por meio de uma conduta situada, a atenção muda de foco, ou seja, deixa-se de olhar para as particularidades internas e individuais e passa-se a observar as interações e por fim as atenções se voltam para uma arena institucional. Quando as atenções focam as arenas institucionais da sociedade, cabe atentar para a afirmação de Goffman (1977, p. 302, tradução minha):

Não são, então, as consequências sociais das diferenças sexuais inatas que precisam ser explicadas, mas a maneira como essas diferenças eram (e são) apresentadas como uma ordem ou um arranjo social, e, mais importante de tudo, a forma como o funcionamento institucional da sociedade assegura que essa contabilidade possa ressoar.

West e Zimmerman (1987, p. 147, tradução minha) definem gênero como um poderoso dispositivo 3 ideológico que produz, reproduz e legitima as escolhas e os limites que estão fundados na categoria sexo: "Uma compreensão de como o gênero é produzido em situações sociais irá permitir a clarificação do estrato interacional da estrutura social e dos processos de controle social que o sustenta".

3 Os autores destacam que não compreendem gênero como "papel" nem como display, sendo esse último termo utilizado por Goffman: "No entanto, nós afirmamos que a noção de gênero como um papel obscurece o trabalho que está envolvido na sua produção nas atividades diárias, enquanto a noção de gênero como um display relega para a periferia o processo de interação" (West; Zimmerman, 1987, p. 127). 
Na busca pela compreensão de como o gênero é socialmente produzido, grande contribuição é apresentada em um estudo de caso elaborado por Garfinkel (1967), em que o autor acompanha a construção de gênero de Agnes, um transexual criado como menino, mas que adotou a identidade feminina aos 17 anos. Para a adoção dessa identitidade feminina, durante um ano ele foi submetido à criação/construção de um gênero feminino, realizada por meio de interações e, por fim, se submetendo a um procedimento cirúrgico para a efetiva mudança de sexo. Em sua trajetória, Agnes teve de inventar, conscientemente, o que a maioria das mulheres faz automaticamente, por exemplo, sendo obrigada a analisar e descobrir como agir dentro de circunstâncias socialmente estruturadas em concepções de feminilidade.

Com base nessa experiência, entre outras, West e Zimmerman (1987) argumentam que o "feminino" e o "masculino" são produtos de eventos culturais. Com essa compreensão, "feminino" e "masculino" podem ser denominados um "processo de atribuição de gênero", em vez de ser definido como um conjunto de características, de comportamentos, ou mesmo de atributos físicos.

Nesse sentido, fazer gênero significa criar diferenças entre e dentro de meninas e meninos e entre e dentro de mulheres e homens; diferenças que não são naturais, nem essenciais e nem biológicas. Uma vez que essas diferenças têm sido construídas, elas são usadas para reforçar a "essencialidade" do gênero.

Em trabalho intitulado "Arranjo entre os sexos" ("The arrangement between the sexes"), Goffman (1977) observa e aponta a criação de uma variedade de estruturas institucionalizadas, por meio das quais a compreensão das diferenças entre os sexos é mantida e ratificada como "natural". O autor indica que esse arranjo é uma questão totalmente cultural, como a divisão de trabalhos, a socialização entre irmãos na família e a segregação dos banheiros. Todas essas características da organização social são apresentadas como consequências naturais da diferença entre os sexos; no entanto, como exemplifica Goffman (1977, p. 316, tradução minha), “[...] a segregação dos toaletes é apresentada como uma consequência natural da diferença entre as classes sexuais, quando na realidade ela é sim um meio de honrar, se não produzir, essa diferença", ou seja, essas características não só permitem a expressão das diferenças "naturais", como são elas próprias que contribuem para a produção da própria diferença.

Para Goffman (1977), em todas as sociedades, a colocação do sexo como categoria inicial está no princípio de um sofrido processo de classificação em que os membros das duas categorias estão sujeitos a um processo de socialização diferenciado. Desde o início, as pessoas que são classificadas como do sexo masculino e as pessoas que são classificadas como do sexo feminino recebem tratamentos diferenciados e adquirem experiências diferentes, bem como gozam e sofrem de expectativas diferentes.

Nesse mesmo sentido, Louro (2008b, p. 15) destaca que a declaração "É uma menina!' ou 'É um menino!' também começa uma espécie de viagem, ou melhor, instala um processo que, supostamente, deve seguir um determinado rumo ou direção", sendo essa declaração compreendida como uma definição, ou decisão, sobre um corpo que inaugura um processo de masculinização ou de feminilização regulado pela cultura na qual está inserido. 
Acompanhar e compreender, com base na perspectiva das crianças, como esse processo é vivido e significado, quais conhecimentos, saberes e elementos sociais e culturais são determinantes nesse processo, torna-se essencial para os estudos sociais da infância, assim como compreender os usos que as crianças dão para esses conhecimentos nas relações que estabelecem com seus pares e também com os adultos.

Além disso, como apontam James e James (2008), desde o nascimento a diferença biológica de sexo traz inscrições para a vida das crianças que as diferenciam em feminino e masculino. $\mathrm{Na}$ busca por compreender como as crianças vivem esse processo, Jordan (1995, p. 72) indica que é preciso diferenciar dois aspectos distintos. Esse processo envolve duas etapas: a primeria, de adoção de uma identidade de gênero; a segunda, de negociação de posicionamento das noçôes de gênero.

Pesquisas (Bussey, 1986 apud Jordan, 1995; Cahill, 1986) têm indicado que essa primeira etapa, relacionada à adoção de uma identidade de gênero, acontece precocemente e que a maioria das crianças tem adotado sua identidade entre 2 e 3 anos de idade, pois nesse momento elas já conseguem se definir como pertencentes a um gênero. Cahill (1986) conduziu diversas pesquisas com crianças pequenas, objetivando identificar as possíveis relações entre a aquisição da linguagem e a aquisição da identidade de gênero. As indicações de Parsons (apud Cahill), de que as categorias idade e gênero são as que mantêm a continuidade da estrutura social, levam Cahill (1986,p. 299, tradução minha) a afirmar: "É provável, portanto, que o sexo e a idade sejam as primeiras dimensões de classificação identitária que as crianças aprendem", ou seja, desde cedo as crianças são confrontadas com pelo menos duas categorias na organização social: o sexo, masculino ou feminino; e a idade, pois desde bebês elas são constantemente diferenciadas dos adultos.

No entanto, as pesquisas também mostram que nessa idade, mesmo já tendo adquirido uma identidade de gênero, as crianças ainda estão muito longe de ter uma noção do posicionamento social implicado em pertencer a determinado gênero, o que seria então a segunda etapa referida por Jordan (1995). As negociações de um posicionamento das noções de gênero envolvem o entendimento de que, embora as crianças se considerem irrevogavelmente membros de um determinado grupo de gênero, elas ainda não têm certeza sobre quais tipos de comportamentos são apropriados para esses membros.

Também Cahill (1986) enfatiza que a compreensão das crianças sobre sua identificação de gênero se dá ao longo da vida e não é baseada em seu conhecimento das coisas físicas e biológicas [genitália], per se, mas sim em seu conhecimento da linguagem de identificação social e cultural que caracteriza a sociedade na qual nascem.

Nas relações sociais que as crianças estabelecem com seus pares no cotidiano de uma instituição de educação infantil, o conceito de posicionamento ${ }^{4}$ para descrever o gênero, segundo Ferreira (2003), constitui-se numa noção essencial. E isso porque

4 McMurray (1998) esclarece que o conceito de posicionamento foi utilizado pela primeira vez por Walkerdine (1981) e Davies (1989), sendo compreendido como possíveis formas de ser. No ponto de vista dos autores, essas interpretações e posicionamentos, ou as formas possíveis de ser, foram relacionados principalmente ao poder e à dominação, portanto, relacionadas ao gênero. 
esse conceito permite compreender que os modos possíveis de as crianças construírem e assumirem o gênero não decorrem de uma inerência biológica concreta nem de uma inerência social abstrata, mas sim porque elas se confrontam e jogam em ações situadas, as quais são múltiplas, complexas, contraditórias e dinâmicas.

Por serem dicotômicas e contraditórias, algumas vezes as crianças se tornam resistentes e desafiam a imposição de estereótipos, noutras vezes atualizam, reproduzem e acentuam esses mesmos estereótipos - até porque, esses posicionamentos são inseparáveis das diferentes posições relativas de poder e dominância que as crianças, entre pares, ocupam nas relações sociais em que se cruzam categorias como gênero, idade, classe social, etnia etc.

Considerando que a categoria gênero - precocemente - faz parte das relações das crianças no âmbito familiar e também no âmbito institucional, pois, como afirma Thorne (1993), para os adultos, gênero é uma categoria útil para classificar, dividir, seriar, juntar as crianças, por isso passa a ser fundamental no âmbito das creches, pré-escolas e escolas, até mais que a estratificação social ou pertença racial. Torna-se assim uma categoria profícua para ser analisada pelo ponto de vista das crianças, ou seja, ser analisada na dinâmica de como esse processo é vivido pelas crianças, quais elementos sociais e culturais marcam esse processo. Como as crianças se utilizam desses conhecimentos nas interações e relações sociais que estabelecem com seus pares e com os adultos em instituições de educação infantil.

Breidenstein (1997, p. 347, tradução minha), com base em estudos de Stefan Hirschauer (1989; 1993a; 1993b; 1994), destaca que:

O predomínio do pertencimento de gênero tem [...], em comparação com outras características, uma maior visibilidade - uma visibilidade que é em parte pelo fato de o pertencimento de gênero utilizar uma representação de atributos que devem ser exteriorizados, e, por outro lado, pelo fato de nossa percepção estar treinada para ver esses atributos.

Essa exteriorização de atributos de gênero, segundo Stefan Hirschauer (1994), são como "marcas" da construção de gênero e ocorrem por meio da linguagem (nomes, títulos e formas de tratamento, pronomes), de artefatos materiais (vestimentas, cosméticos, bijuterias, acessórios) e de gestos e atividades. Ao nascerem, as crianças têm seu sexo definido pela genitália; todavia, no dia a dia essa parte do corpo está coberta, ${ }^{5}$ o que leva à conclusão de que não se pode definir o sexo por esse meio simplesmente porque ele não é visualizado. Então, já que o definidor do pertencimento sexual - os genitais não está visível no cotidiano, as crianças vão reconhecendo e definindo o gênero em si mesmas e nos outros, por meio de objetos, acessórios, cortes de cabelo, gestos, voz, entres outros. Hirschauer (1993b) enfatiza que o pertencimento de gênero de uma pessoa é

5 Considerando-se particularmente as sociedades ocidentais, embora se deva relativizar o grau de abrangência de tal uso cultural. 
uma qualidade que só pode ser mantida por meio desses objetos culturais sexualmente marcados: vestimentas, linguagem, gestos, atividades etc.

Louro (2008b, p. 83, aspas do original) destaca que, mesmo que essa "marcação" tenha sido estabelecida arbitrariamente como adequada e legítima em uma sociedade, é, no entanto, "[...] pouco relevante definir quem tem a iniciativa dessa 'marcação' ou quais suas intenções, o que importa é examinar como ocorrem esses processos e seus efeitos”. Nesse sentido, no grupo de crianças envolvido nesta pesquisa, ao me atentar para as relações sociais estabelecidas entre elas, a intenção foi identificar como esse processo é vivido, quais seus efeitos e, sobretudo, como as crianças se utilizam desses conhecimentos nas interações e relações sociais estabelecidas com seus pares e com os adultos.

\section{APROXIMAÇÕES À PERSPECTIVA DAS CRIANÇAS QUANTO AO GÊNERO}

Nesse grupo de crianças, o interesse pelas definições e construções de gênero esteve marcado pelos objetos, pelas vestimentas e acessórios, como é possível acompanhar no excerto a seguir:

Helena $^{6}$ chega à sala com uma roupa de fada [saia, varinha e coroa]. Léo, ao vê-la com a roupa que chamou a atenção das outras crianças, diz:

Léo: Eu também vou comprar uma saia.

Helena: Não, tu é menino!

Isadora: Só menina que pode! [Isadora está perto e participa da conversa].

Léo observa as duas, mas não fala nada.

Antes de irem ao parque, as crianças vão ao banheiro e lá a discussão continua. Willian vai ao banheiro pegar uma moto e um carrinho que estão dentro do box e ao ver Helena fala:

Willian: Que bonita, Helena!

Willian olha para Helena e, observando sua roupa, sorri; depois sai.

Helena e Larissa estão sentadas no vaso sanitário fazendo xixi. Quando Manu chega ao banheiro para fazer xixi, fala olhando para mim:

Manu: Eu tô de saia, eu tenho que levantar para fazer xixi.

Helena: Minha saia incomoda.

Helena percebe que Manu olha para sua saia e pergunta:

Helena: Tu gostou, Manu?

Em seguida, Helena volta a se certificar de que saia não é para menino perguntando para Manu:

Helena: Saia é de menina, né?

6 Considerando questões éticas e aspectos de autoria e autorização (Kramer, 2002), utilizo o primeiro nome das crianças - em algumas situações, utilizo o apelido usado entre as próprias crianças em seus diálogos e relações -, mas não revelando o sobrenome e omitindo o nome da instituição onde a pesquisa ocorreu. 
Antes que Manu respondesse, Isadora, que está mais longe, mas participa da conversa, se aproxima de Helena e diz:

Isadora: Isso também é de menina, né? [referindo-se à coroa que Helena usa].

Manu: Saia é de menina; o que é de menina, menino não pode usar!

Manu fala essa frase olhando para mim, suponho que pretendia ver se eu concordava ou não, mas não me manifestei.

Helena: É!

Em seguida, elas vão para o parque.

(Registro de campo, 19 out. 2009)

Entre as crianças, o uso dos conhecimentos relativos às noções de gênero era permeado pelos objetos, fossem eles sandálias, saias, batons, acessórios diversos e demais artigos que algumas vezes somente se diferenciavam pelas cores azul ou rosa.

No registro do episódio descrito anteriormente, as meninas buscaram legitimar seus conhecimentos e noções de gênero entre elas mesmas. Helena chegou com uma saia de fada e chamando a atenção de todas as crianças, inclusive de um menino, Léo, que logo afirmou que sua mãe também iria comprar uma saia para ele, mas Helena foi categórica ao informar que ele era um menino, deixando transparecer com isso que ela subentendia que ele não podia usar saias. Isadora logo se aproximou ratificando que somente meninas podiam usar saias.

Depois, outro menino, Willian, ao olhar para Helena e admirar a beleza de sua saia, disse: “Que bonita, Helena!", mesmo ele não falando que queria comprar uma saia, assim como Léo havia afirmado, Helena, na sequência da conversa com Manu, procurou reafirmar sua noção e ideia de que saias eram de meninas. Manu, por sua vez, foi ainda mais categórica na afirmação: “o que é de menina, menino não pode usar". Pela análise desses episódios, é possível se verificar a construção das noções de gênero entre as crianças por meio de uma visualização e, sobretudo, de uma exteriorização de atributos de gênero. Sendo essa prática algo que elas fazem recorrentemente ao estabelecerem relações com os outros, sejam esses outros meninos ou meninas ou ainda adultos homens ou mulheres.

Como já afirmado anteriormente, tão importante como compreender o que as crianças sabem e aprendem sobre gênero, é compreender os usos que elas dão a esse conhecimento nas relações que estabelecem com seus pares e também com os adultos. É importante destacar que, ao mesmo tempo em que o gênero é construído nas relações e interações sociais, ele é também permeado por estereótipos. Morrow (2006, p. 99, tradução minha) afirma que:

Crianças tendem a mostrar pontos de vistas estereotipados muito fixos sobre as diferenças de gênero, e é importante tomar nota disso, porque, como as crianças esperam que as outras crianças se comportem e reajam, é provável que reforcem estereótipos de gênero.

No processo de negociações de posicionamento de gênero, as crianças procuram em si, e sobretudo nos outros, o reconhecimento dos artefatos materiais, como vestimentas, cortes de cabelo, acessórios, linguagens e gestos referentes ao gênero em questão. 
No grupo de crianças que compôs a presente pesquisa, o número de meninas e meninos apresentou uma grande diferença na distribuição de gênero: 12 meninas e 3 meninos. Talvez essa diferença na distribuição tenha contribuído para uma não definição de brincadeiras dos meninos e brincadeiras das meninas, bem como uma não definição da ocupação dos espaços das meninas e dos meninos, tanto dentro da sala como nos espaços externos da instituição.

Durante o tempo em que estive em campo, os meninos Willian, Leonardo e Alan esporadicamente brincavam juntos de futebol, de bicicleta e nos brinquedos do parque. Na maioria do tempo, eles brincavam com as meninas, havendo algumas poucas situações em que as fronteiras de gênero, definidas por Thorne (1993), foram evidenciadas na pesquisa, que não serão aqui abordadas considerando os limites do artigo. Alan esteve doente por diversas vezes e por esse motivo não frequentava assiduamente a instituição, mas quando estava presente brincava tanto com os meninos como com as meninas.

Em algumas situações, observei as meninas construindo um espaço de brincadeira em que a entrada de Leonardo não fora permitida, mas a entrada do outro menino, o Willian, foi desejada e solicitada por elas. Em seus estudos, Thorne (1993) afirma que a separação espacial de meninos e meninas constitui uma espécie de fronteira, que talvez seja mais fortemente sentida por aquelas crianças que querem participar de uma atividade controlada pelo outro sexo. Quando as meninas e os meninos estão juntos, de forma descontraída e integrada, o sentido de gênero como fronteira muitas vezes se dissolve. Mas, outras vezes, as meninas e os meninos se reúnem de maneira que enfatizam suas oposições. Thorne (1993, p. 64, tradução minha) destaca que “[...] embora o contato, por vezes, enfraqueça e reduza um sentido ativo de diferença, os grupos podem também, por meio da interatividade com o outro, fortalecer suas fronteiras".

Como já afirmei, na grande maioria das interações observadas, nos nove meses de pesquisa de campo, houve a predominância de episódios em que meninos e meninas interagiam entre si, não sendo observado um grupo constituído apenas de meninas ou apenas de meninos. Considero o reduzido número de meninos e também a idade das crianças fatores determinantes para esse fato, pois nessa idade as crianças se encontram em processo de constituição de suas noções de posicionamento de gênero. No entanto, essa configuração do grupo também traz elementos importantes para se compreender o modo como meninos e meninas, nas interações que estabelecem, constroem ativamente seu gênero, bem como experimentam diferentes formas de ser menino ou menina num contexto institucional.

\section{AS “MARCAS” DOS ARTEFATOS MATERIAIS}

Assim como no episódio anterior, em que Helena chega à instituição com uma saia que chama a atenção das meninas e também dos meninos Willian e Léo, outros episódios durante minha estada em campo envolveram a "marca" dos artefatos materiais na constituição e construção da identidade de gênero: 
Assim que acordam, as crianças são orientadas pelos adultos para irem ao banheiro fazer xixi. Em seguida elas calçam seus sapatos, que ficam guardados em um cesto de vime. Quando observo Willian, que brinca com Amanda, percebo que ele está com as sapatilhas de uma menina. Amanda também o observa intrigada. Olho para ele, que logo me esclarece:

Willian: É da Letícia, eu tô usando... o meu é tênis.

Amanda o observa um pouco intrigada, mas não fala nada, somente sorri para ele e ambos continuam a brincar com ursinhos; cada um tem um urso de pelúcia. Willian, calçando as sapatilhas de Letícia, senta sobre seu urso e brinca com um jogo de memória. Para ir ao refeitório lanchar, eu ajudo Willian a colocar as meias nos pés e ele novamente coloca as sapatilhas de Letícia. Depois do lanche, quando Letícia acorda, Manu é a primeira a informá-la da situação, quando ela ainda está deitada no colchão:

Manu: O Willian pegou teu sapato, Letícia!

Willian caminha na direção de Letícia e lhe entrega os sapatos. Letícia diz:

Letícia: Você pegou meu sapatinho de cristal!

Letícia fala sem demonstrar ter ficado incomodada; em seguida, levanta, calça seus sapatinhos e vai ao banheiro, retornando em seguida para ouvir a história que será contada pela professora. Willian coloca seu tênis. (Registro de campo, 31 ago. 2009)

Os episódios quase sempre envolveram o menino Willian, que insistentemente fazia uso de "artefatos materiais" reconhecidos como do gênero feminino. O uso das sapatilhas de Letícia foi a primeira de uma série de situações em que ele procurava experimentar os calçados das meninas. No episódio anterior não houve, de forma enfática, nenhuma manifestação das meninas, nem dos outros meninos e nem dos adultos, de que ele não deveria usar a sapatilha. No entanto, meu olhar curioso em sua direção o levou a explicar que as sapatilhas eram de Letícia. A rápida comunicação de Manu sobre o acontecimento, imediatamente depois que Letícia acorda de seu sono, evidenciou que o fato havia chamado a sua atenção e possivelmente de outras crianças que, no entanto, não se manifestaram.

Retomando a diferenciação feita por Jordan (1995), é possível inferir no episódio anterior o envolvimento de Willian num processo de negociação da noção de gênero. Mesmo que ele já tenha uma definição de pertencimento e identidade ${ }^{7}$ de gênero, manifestando seus interesses de acordo com esse pertencimento e se definindo como menino em diversas situações observadas, ele pode ainda não ter uma compreensão do posicionamento a ser tomado e das noções e estereótipos de gênero que se fazem visíveis, sobretudo por meio dos artefatos materiais; e nesse processo ele vai também construindo uma noção de posicionamento e pertencimento de gênero.

Outra interpretação possível é de que ele já tenha sim uma noção desse posicionamento de gênero, dessas formas de ser, mas, no entanto, se utiliza dessas ações sociais

7 Sem desconsiderar que, como destaca Louro (1997), essas identidades são sempre construídas e por isso mesmo inacabadas, instáveis e passíveis de transformação. 
para experimentar e ocupar lugares sociais diferentes e também estar com as meninas, ou seja, ser aceito por elas, pois, como já afirmado, essa noção de posicionamento se entrecruza com outras categorias e posições relativas de poder e desejo.

Ações como as demonstradas por Willian são chamadas de ações de "fronteira", segundo Thorne (1993). Para a autora, essas ações podem ser definidas como um processo por meio do qual um menino ou uma menina pode solicitar o acesso a grupos e atividades do outro sexo. Thorne (1993) salienta que cuidadosamente escolheu a palavra "fronteira" para aludir a esse processo, pois considera a palavra "passagem" inadequada porque, em situações observadas por ela, meninos e meninas não pretendiam ser do outro sexo. Da mesma forma que eles também não reivindicavam uma espécie de "terceiro sexo", status encontrado em algumas outras culturas, embora possa ter uma mistura de atributos estereotipados associados com várias formas de masculinidade e feminilidade.

Thorne (1993) destaca que é nesse processo de fronteira em que muitas vezes os meninos que buscam participar e acessar as brincadeiras das meninas são denominados de sissy ou, numa denominação correspondente em português, de "maricas" e as meninas são denominadas de tomboy ou "menina moleque". Na presente pesquisa, mesmo sendo recorrentes os episódios em que Willian procurava participar das brincadeiras e de outras situações no grupo das meninas, o termo sissy ou "maricas", nunca foi observado ou associado às ações do menino, nem pelas outras crianças, nem pelos adultos.

As ações de fronteira do menino Willian foram recorrentemente observadas no período da pesquisa de campo. Situações semelhantes às descritas anteriormente foram presenciadas em diversas ocasiões e em alguns momentos as meninas trocaram os calçados com Willian, mas em outros se manifestaram veemente contra, justificando que eram de meninas, como veremos no excerto a seguir:

Depois do parque, as crianças voltam para a sala, lavam as mãos e em seguida almoçam. As meninas se sentam no tapete e começam novamente um troca-troca de calçados. Letícia, Amanda, Manu, Nicole, Camila e Bianca estão sentadas em círculo no tapete. Willian termina de lavar suas mãos, junta-se a elas e fala:

Willian: Eu também quero trocar.

Willian tira suas sandálias e pega uma das meninas, mas Camila fala:

Camila: Não, esse é de menina!

Quando Willian pega outras sandálias para calçar, ela observa novamente:

Camila: Esse também é de menina!

Com a definição de Camila, Willian acaba não trocando as sandálias, fica com as suas e segue para o refeitório com elas.

(Registro de campo, 17 nov. 2009)

Para Willian, na situação descrita, o pertencimento de gênero lhe impossibilita de participar da troca de sandálias. Por isso aponto o gênero como um possibilitador ou limitador das ações sociais das crianças. Parece que o fato de Willian, mesmo se reconhecendo como menino, insistentemente ousar experimentar saias, batons, sandálias e outros elementos, todos social e culturalmente definidos e reafirmados pela ordem 
social emergente ${ }^{8}$ das meninas do grupo como sendo femininos, constitui-se em uma possibilidade - no contexto do grupo composto por uma maioria de meninas - de estar com elas e fazerem algo juntos, ou seja, de ocupar lugares sociais diferentes e ao mesmo tempo ser aceito e pertencer ao grupo. No entanto, por meio das constantes reprimendas das meninas, nesse processo Willian - o que não exclui as meninas - vai ao mesmo tempo negociando, constituindo e atualizando seus posicionamentos e suas noções e percepções de gênero.

No entanto, a própria ordem social emergente, criada entre e pelas meninas, em raras situações foi quebrada ou promoveu o uso das sandálias pelo menino Willian, indicando que esse processo de posicionamento, de construção e definição de pertencimento de gênero é complexo, fragmentado, instável, por isso em constante transformação e também permeado pelo entrecruzamento de outras categorias e por posições relativas de poder e dominância - aqui, no caso, aliado aos desejos.

As crianças Willian, Bianca, Amanda, Ana Laura e Nicole estão na casinha do parque e brincam com um jogo do Batman como se fosse um jogo de memória; todavia, as peças ficam viradas para cima e cada criança pode escolher as duas peças que desejam. Observo que Nicole está usando as sandálias de Willian, e ele está descalço. Logo em seguida, Ana Laura convida Willian, Amanda, Bianca e Nicole para irem até a sala do Grupo 4, onde se ouve música e as crianças dançam e brincam. No caminho até lá, Willian pede suas sandálias, pois seus pés estão doendo ao caminhar na areia. Nicole quer continuar usando as sandálias de Willian e então pede para ficarem com os sapatos trocados. Voltam até a casinha e Nicole oferece suas sapatilhas para Willian e, quando ela as coloca nos pés dele, diz:

Nicole: Ficou lindo, Willian. Ficou lindo, Willian... olha aqui [fala para mim] Em seguida caminham até onde estão Bianca e Ana Laura.

(Registro de campo, 5 nov. 2009)

Destaco as relações de poder e os desejos, pois, no caso desse episódio, o uso das sapatilhas só foi incentivado e concedido como meio estratégico de garantir e manter a condição e o uso de algo desejado. A iniciativa e o interesse de Willian desencadeou no grupo das meninas uma brincadeira de troca de sandálias, mas em alguns momentos ele era excluído dessa possibilidade. Por meio das relações estabelecidas com as meninas e das indicações dadas por elas - ordem social emergente -, de que ele não poderia usar as sandálias, que são/estão definidas cultural e socialmente como femininas, a possibilidade de agir e participar do mundo social delas é limitada

8 Vale reafirmar que utilizo esse conceito com base em Ferreira (2002; 2004), que compreende que as crianças, ao se encontrarem regular e rotineiramente no mesmo contexto institucional e realizarem cotidianamente atividades conjuntas e ordenadas que satisfazem expectativas comuns e recíprocas, geram em suas práticas e relações uma ordem social emergente, a qual é socialmente convencionada por elas mesmas, regulando e organizando as ações individuais e coletivas desse grupo. 
e cerceada pela condição de gênero e pelo grupo de meninas, que mantém, reforça e reproduz estereótipos de noções de gênero nas relações e regras que estabelecem.

Nesse episódio, torna-se evidente a premissa afirmada anteriormente: nas relações sociais que as crianças estabelecem entre pares, o conceito de posicionamento para descrever o gênero se constitui numa noção essencial; e nesse posicionamento as crianças se confrontam e jogam em ações situadas, que são múltiplas, complexas, contraditórias e dinâmicas, de tal sorte que algumas vezes as crianças se tornam resistentes e desafiam a imposição de estereótipos, noutras vezes atualizam, reproduzem e acentuam esses mesmos estereótipos - sobretudo porque esses posicionamentos não são separáveis das diferentes posições relativas de poder e dominância que as crianças, entre pares, ocupam nas relações sociais. Para ilustrar, no caso citado temos Nicole, em uma ação estratégica (Dubet, 1994), quando para realizar um desejo seu, ou seja, o de permanecer usando as sandálias de Willian, resiste e desafia a imposição de regras e ações que afirmam os estereótipos definidos anteriormente pela ordem social emergente entre as meninas do grupo.

Diferentemente do que ocorre na sociedade ocidental, uma exceção pode ser citada com o que ocorre na sociedade hausa, em que Schildkrout (1978) aponta que às crianças é permitido se socializarem em uma perspectiva de variação da abordagem tradicional, sobretudo no que se refere à categoria gênero. $\mathrm{O}$ autor salienta ter percebido em sua pesquisa que as crianças hausas não fazem simples imitação dos adultos, como num ensaio para a vida crescida. A infância hausa é qualitativamente diferente da maioridade, pois as crianças não têm de observar muitas das regras que regulam o comportamento dos adultos, principalmente as concernentes ao gênero.

Atentando para as relações de gênero na infância na sociedade hausa, o autor observa que, diferentemente dos adultos, entre os quais a sociedade opera uma separação radical de gêneros, as crianças têm contato com o universo feminino e masculino, podendo andar livremente pelos dois espaços, tanto no das mulheres como no dos homens. Essa possibilidade dada às crianças faz com que elas desempenhem nessa sociedade um papel central na comunicação, nas relações entre os dois gêneros e também uma contribuição significativa para a atividade econômica dessa sociedade, pois, como os adultos são cerceados da possibilidade de contato entre os gêneros, é delegada às crianças a tarefa de levar encomendas, compras, recados etc.

A tentativa de Willian de participar do grupo das meninas e de também usar os mesmos artefatos materiais não se restringia ao uso das sandálias e sapatos das meninas, mas permeava outros objetos, como usar lápis de cor rosa para fazer seus desenhos, usar camiseta com desenho da personagem Minnie - e logo as meninas indicavam que ele só poderia usar camiseta com desenho do Mickey-, tomar água de garrafas personalizadas de Cinderela, Branca de Neve; todas essas situações também geraram conflitos entre o menino Willian e as meninas. Além desses artefatos materiais, também houve um episódio envolvendo um gloss labial: 
$\mathrm{Na}$ volta do refeitório, Nicole pega seu batom - gloss - da mochila, passa em seus lábios e nos das amigas. Estou abaixada para conversar com Manu sobre sua tiara de cabelo e Nicole passa batom em mim também. Willian observa e fala:

Willian: Eu quero passar também, Nicole.

Nicole: Não, tu é menino Willian, não pode!

Willian: Mas pode passar em todo mundo.

Willian faz essa afirmação para Nicole e depois olha para mim e pergunta:

Willian: Pode passar em todo mundo, né?

Balanço a cabeça afirmativamente, enquanto Nicole passa batom em mim. Willian então sorri e olha para Nicole, que também sorri e balança a cabeça negativamente. Nicole sai com seu batom sem passá-lo nos lábios de Willian, guardando-o em sua mochila.

(Registro de campo, 9 nov. 2009)

Nesse episódio, a impossibilidade de Willian participar do uso do gloss foi estrategicamente acompanhada da utilização de uma regra recorrente em contextos educativos: "tudo é de todos". ${ }^{9}$ Ao lançar esse argumento, Willian, numa ação estratégica, buscou uma possibilidade de também poder passar o gloss, mesmo sendo um menino. Ou seja, como afirma Dubet (1994, p. 123), a ação estratégica “[...] visa conceder os meios para as finalidades pretendidas nas oportunidades abertas pela situação". Novamente é possível identificar que nesse posicionamento de gênero estão entrelaçadas outras posições relativas de poder e dominação; por um lado, Willian recorre a uma regra e poder definidos no grupo e, por outro, Nicole está como a "dona” e proprietária do gloss. Nessa ação social estratégica de Willian, ele resgata o conhecimento e a convenção institucionalizada de "tudo é de todos" no contexto da creche para poder também participar do uso do gloss. Todavia, para Nicole, a "dona” do gloss, a convenção de noções de gênero, definida pelas crianças em sua ordem social emergente, ganha mais peso que a convenção "tudo é de todos" na creche.

Tenho apontado, com base nos episódios observados em campo, que as experiências nas relações estabelecidas entre crianças, tendo como foco da atenção os artefatos materiais, vão indicando e "marcando" o pertencimento de gênero de meninos e meninas, e nesse processo elas vão constituindo suas noções de gênero.

Ser um menino em um contexto que envolve 12 meninas, no entanto, limita as possibilidades de ação social, como uma estrutura criada pela própria ordem emergente das meninas ao reproduzirem estereótipos sociais e culturais sobre noções de gênero. Paradoxalmente, essa ordem social emergente elaborada pelas meninas leva Willian a criar estratégias mais elaboradas de ação social, confirmando a afirmação de James, Jenks e Prout (1998), de que os contextos estruturais, nos quais as crianças se encontram, não apenas restringem suas ações, mas também as possibilitam.

9 Trata-se de uma regra tácita que vigora, sobretudo em espaços educativos públicos, como estratégia para trabalhar o aspecto coletivo das relações, bem como evitar conflitos e disputas por brinquedos e objetos entre as crianças. 
As estratégias - cada vez mais elaboradas - criadas por Willian também apontam, no campo da educação infantil, uma série de conhecimentos que as crianças mobilizam ao se relacionarem e interagirem cotidianamente entre pares e também com os adultos, indicando que essas relações são também educativas. Para ajudar nessa compreensão, acredito ser de grande contribuição a concepção de intencionalidade da ação como processo proposta por Giddens (2000). Com base nessa ideia, o central a ser observado é que cada ator racionaliza sua ação não somente anterior e previamente, mas, sobretudo, posteriormente ou durante o fluxo da própria ação. Essa concepção também traz elementos fundamentais para que no cotidiano se reconheçam e legitimem as ações das crianças, bem como a dos adultos, que da mesma forma muitas vezes só têm capacidade de definir discursivamente e racionalmente suas ações no seu acontecer, no seu processo.

Com base nesse conceito de intencionalidade da ação como processo (Giddens, 2000; 2002), é possível também compreender que os sentidos da ação - como as ações de Willian descritas nos episódios anteriores - não se referem aos interesses, às intenções e razões que são expressas de forma isolada pelos atores, mas sim como inerentes e fazendo parte de um processo de reflexão interativo na ação, ou seja, no seu decorrer e não somente previamente sobre a ação a ser realizada.

Essa reflexão na ação é definida por Giddens (2000) como monitorização reflexiva da ação e também é considerada fundamental para o campo da educação infantil, pois aponta para a necessidade de o professor estar atento a todo o cenário da interação e não apenas ao comportamento de atores particulares, analisando-os separadamente. Isso justifica por que é necessário analisar e compreender não as ações de Willian isoladamente, mas sim dentro do grupo das meninas e também nas relações com os outros meninos.

Durante nove meses, acompanhei muitas iniciativas e estratégias de Willian em confrontar o uso de artefatos materiais, definidos social e culturalmente como de meninas, sendo essas definições constantemente reafirmadas pelas meninas do grupo. Alguns dias antes de encerrar o período da pesquisa de campo, acompanhei o seguinte episódio:

Helena, sentada a uma mesinha de plástico que está próximo da estante num canto oposto à entrada do banheiro, tem à sua frente materiais de sucata, como potes de plástico e garrafas de suco vazias, e fala com Bianca, que desenha sentada a uma outra mesa. Nessa mesma mesa, no outro lado, está Willian, que brinca com um telefone azul e outros objetos; Léo também está próximo dele, mas eles não brincam juntos.

Helena: Eu trouxe comida bem gostosa para você.

Bibi continua a desenhar e em seguida fala:

Bibi: Onde tu vai, amiga?

Nicole chega com uma bolsa e um boneco bebê e o entrega para Helena dizendo:

Nicole: Eu tenho que trabalhar!

Nicole sai apressada e volta com um pacote vazio de ração para cachorro, entrega para Helena e diz:

Nicole: Preciso ir; preciso fazer xixi. 
Nicole sai apressada, mas não vai ao banheiro, o que me dá indicações de que a fala fazia parte do faz de conta.

Helena: Eu tenho que ir ao mercado.

Nicole sai e Helena chama de onde está:

Helena: Nicole, o bandido está vindo pegar teu bebê.

Nicole, que caminha pela sala encenando o faz de conta, se aproxima de Willian, que brinca do outro lado da mesa com seu telefone azul. Nicole, sem avisar e nem pedir, tenta pegar o telefone de Willian. $\mathrm{Na}$ emergência de perder seu brinquedo, Willian fala:

Willian: Fui eu quem peguei! É de menino! Não é de menina!

A professora ouve a conversa e medeia a situação para que Willian empreste o brinquedo para Nicole. Então ele o empresta.

Helena continua a chamar:

Helena: Vem, Nicole.

Nicole: Oi Helena, tô aqui [fala com Helena pelo telefone azul que conseguiu de Willian].

Em seguida, Nicole vem para perto de Helena, mas logo sai. Léo também se aproxima de Helena com um celular que lembra um rádio de polícia, coloca-o perto da boca da menina e fala:

Léo: Ohhh, a polícia e o bombeiro.

Helena fala ao celular como se ele fosse um rádio:

Helena: Ohhh, polícia vem aqui que o bandido está comendo o bebê.

(Registro de campo, 16 nov. 2009)

Pela primeira vez, presenciei Willian utilizando a mesma estratégia das meninas, reproduzindo estereótipos de noções de gênero para que pudesse continuar utilizando um brinquedo que, no caso, era da cor azul e por isso poderia ser definido como sendo de menino. Todavia, sua tentativa foi frustrada pela mediação da professora, que o orientou a emprestar o telefone para Nicole, mas de todo modo o episódio revela que, como alerta Ferreira (2003, p. 5, grifo do original), é preciso “[...] não desconsiderar que as crianças agem sob influência de um contexto social mais vasto que exalta a masculinidade hegemónica", revelando os jogos de poder e a sua relação com o gênero.

Gostaria de retomar a afirmação de West e Zimmerman (1987), quando definem gênero como uma realização de rotina, metódica e recorrente, e que esse realizar e "fazer" gênero é produzido tanto pelas mulheres como pelos homens, que como membros da sociedade passam a ser reféns de sua produção. Willian, ao "fazer" gênero, afirmando que o telefone azul era de menino e que por isso meninas não podiam usá-lo, tornou-se refém de sua própria criação, pois, na busca pela possibilidade de permanecer com seu brinquedo naquele momento, contribuiu para a reprodução social. Assim, as ações executadas e os discursos adotados para atingir fins particulares, em situações particulares, têm como consequência - não intencional - reproduzir as estruturas da sociedade, pois, como destaca Arendt (1987, p. 244), os homens “[...] nunca foram e jamais serão capazes de desfazer ou sequer controlar com segurança os processos que desencadeiam através 
da ação". Nesse episódio, por meio de sua ação social, Willian acabou contribuindo e atualizando a produção da uniformidade de comportamento de gênero.

West e Zimmerman (1987) indicam que dessa forma os novos membros da sociedade passam a se envolver em um processo de autorregulação, no qual começam a monitorar a conduta de si mesmos, bem como a conduta dos outros em relação a suas implicações de gênero. Assim, as diferenças de gênero ou a formação sociocultural de essencialismos de naturezas femininas e masculinas alcançam o status de fatos objetivos dentro de uma ordem social.

\section{CONSIDERAÇÕES FINAIS}

Como indicado no início do texto, procurei apresentar aqui resultados de uma pesquisa que objetivou investigar entre crianças as formas, as significações e as vias de transmissão de elementos culturais e sociais que envolvem a dimensão corporal, bem como a emergência de novos elementos que reforçam, modificam, multiplicam, transformam, transgridem e transcendem ou simplesmente ocultam aqueles já estabelecidos. Dirigindo minha atenção às indicações dadas pelas crianças, identifiquei a categoria gênero como sendo uma categoria central e constituidora de suas relações e de suas possibilidades de ação social.

Além da centralidade dessa categoria observada nas relações estabelecidas entre as crianças, foi possível, por meio dos episódios apresentados, perceber que o pertencimento e as noções de posicionamento de gênero envolvem uma variedade de conhecimentos e elementos sociais e culturais. Conhecimentos, saberes e elementos sociais e culturais que adquirem num contexto educativo de educação infantil um valor pedagógico, sendo fundamental ao professor observar e compreender os usos que as crianças dão ou fazem desses conhecimentos nas suas relações sociais.

Por meio dos episódios analisados, foi possível identificar a riqueza de nuanças e contradições que permeiam o processo de construção de gênero. Nesse processo, a noção de posicionamento se apresenta como uma noção essencial porque permite compreender que os modos possíveis das crianças construírem e assumirem o gênero não decorrem de uma inerência biológica concreta, nem de uma inerência social abstrata, mas sim porque se confrontam e jogam em ações situadas, as quais são múltiplas, complexas, contraditórias e dinâmicas.

Por serem dicotômicas e contraditórias, por vezes as crianças se tornam resistentes e desafiam com ações inovadoras e contestadoras a imposição de estereótipos e elementos sociais e culturais, como foi possível observar em diversos episódios apresentados. Noutras vezes, atualizam, reproduzem e acentuam esses mesmos estereótipos, como no último episódio apresentado, quando Willian contribuiu com essa reprodução ao definir o telefone azul como de menino para poder com ele permanecer, pois, como também já afirmado, esses posicionamentos são inseparáveis das diferentes posições relativas de poder e dominância que as crianças, entre pares, ocupam nas relações sociais.

Ao aprofundar os estudos e pesquisas sobre os modos próprios de as crianças criarem entre elas uma realidade alternativa à ordem institucional adulta, verifiquei que 
elas efetivamente instituem uma ordem social emergente, que tem como referência valores e regras sociais delas mesmas. Essa ordem social emergente revela que as crianças não se limitam a reproduzir o mundo dos adultos, mas também o reconstroem e o ressignificam por meio de múltiplas e complexas interações com os pares, o que permite identificá-las não só como reprodutoras desse mundo, mas também como autoras de sua própria infância.

\section{REFERÊNCIAS}

Arendt, Hannah. A condição humana. Rio de Janeiro: Forense-Universitária, 1987.

Breidenstein, Georg. Der Gebrauch der Geschlechterunterscheidung in der Schulklasse. Zeitscbrift für Soziologie, Stuttgart: F. Enke Verlag Stuttgart, Jg. 26, Heft 5, S. 337-351, Oktober, 1997.

CAHILl, Spencer. Language practices and self-definition: the case of gender identity acquisition. The Sociological Quarterly, [S.1.]: Universty of California Press, JAI Press, v. 27, n. 3, p. 295-311, 1986.

Connell, Robert. Políticas da masculinidade. Educação E̊ Realidade, Porto Alegre: UFRGS, v. 20, n. 2, p. 185-206, 1995.

Corsaro, Willian A. Reprodução interpretativa e cultura de pares. In: MüLler, Fernanda; Carvalho, Ana Maria Almeida (Orgs.). Teoria e prática na pesquisa com crianças: diálogos com Willian Corsaro. São Paulo: Cortez, 2009. p. 31-50.

DANBY, Susan. The serious and playful work of gender: talk and social order in a preschool classroom. In: Yelland, Nicola. Gender in early childhood. 2. ed. London and New York: Routledge, 2005.p. 175-205.

DAvies, Bronwyn. Frogs and snails and feminist tales: preschool children and gender. Sydney, Australia: Allen \& Unwin, 1989.

DubEt, François. Sociologia da experiência. Lisboa: Instituto Piaget, 1994.

FARIA, Ana Lúcia Goulart de. Pequena infância, educação e gênero: subsídios para um estado da arte. Cadernos Pagu, Campinas: UNICAMP, n. 26, p. 279-287, 2006.

Felipe, Jane. Sexualidade nos livros infantis: relações de gênero e outras implicações. In: Meyer, Dagmar (Org.). Saúde e sexualidade na escola. Porto Alegre: Mediação, 1998. p. 111-124.

.Erotização dos corpos infantis. In: Louro, Guacira Lopes; Felipe,Jane; Goellner, Silvana (Orgs.). Corpo, gênero, sexualidade: um debate contemporâneo na educação. 2. ed. Petrópolis: Vozes, 2005. p. 53-65.

. Gênero, sexualidade e a produção de pesquisas no campo da educação: possibilidades, limites e a formulação de políticas públicas. Pro-Posições, Campinas: UNICAMP, v. 18, n. 2 (53), p. 77-87, 2007.

. Gênero e sexualidade nas pedagogias culturais: implicações para a educação infantil. 2011. UDESC, Florianópolis. Disponível em: <http://cce.udesc.br/titosena/Arquivos/ Artigos_gensex/SexualidadeInfantil.pdf $>$. Acesso em: 5 ago. 2011. 
Ferreira, Maria Manuela Martinho. "-A gente aquio que gosta mais éde brincar com os outros meninos!": as crianças como atores sociais e a (re)organização social do grupo de pares no cotidiano de um jardim de infância. 2002.736 f.Tese (Doutorado em Ciências da Educação) - Universidade do Porto, Faculdade de Psicologia e Ciências da Educação, Porto, 2002.

. O trabalho de fronteira nas relaçóes entre géneros como processo estruturante de identidades homo e heterossociais de género ocorridas nas brincadeiras entre crianças em espaços de "brincar ao faz de conta" num JI. Faculdade de Psicologia e de Ciências da Educação, Universidade do Porto, Portugal, 2003. Disponível em: <www.fpce.up.pt/ciie/publs/artigos/fronteira.doc>. Acesso em: 8 jul. 2010.

. Do "avesso" do brincar ou... as relações entre pares, as rotinas da cultura infantil e a construção da(s) ordem(ens) social(ais) instituintes(s) das crianças no jardim de infância. In: Sarmento, Manuel Jacinto; Cerisara, Ana Beatriz. Crianças e miúdos: perspectivas sociopedagógicas da infância e educação. Porto: Edições ASA, 2004. p. 55- 104.

Finco, Daniela. Faca sem ponta, galinha sem pé, homem com homem mulher com mulher: relações de gênero nas brincadeiras numa pré-escola de Campinas. 2004. 165 f.Dissertação (Mestrado em Educação) - Faculdade de Educação, Universidade Estadual de Campinas, Campinas, 2004.

.Educação infantil, espaços de confronto e convivio com as diferenças: análise das interações entre professoras e meninas e meninos que transgridem as fronteiras de gênero. 2010.195 f. Tese (Doutorado em Educação) - Faculdade de Educação, Universidade de São Paulo, São Paulo, 2010.

Garfinkel, Harold. Studies in ethnomethodology. Englewood Cliffs: Prentice-Hall, 1967. Giddens, Anthony. Dualidade da estrutura: agência e estrutura. Porto: Celta, 2000.

. Modernidade e identidade. Rio de Janeiro: Jorge Zahar Editor, 2002.

Gовві, Marcia. Lápis vermelho é de mulherzinha: relações de gênero, desenho infantil e pré-escola. 1997. Dissertação (Mestrado) - Faculdade de Educação, Universidade Estadual de Campinas, Campinas, 1997.

Goffman, Erving. The arrangement between the sexes. Theory and Society, Springer [S.1.]: v. 4, n. 3, p. 301-331, 1977.

Graue,M. Elizabeth;WALSH,Daniel J. Investigação etnográfica com crianças: teorias, métodos e ética. Lisboa: Fundação Calouste Gulbenkian, 2003.

Hirschauer, Stefan. Die interaktive Konstruktion von Geschlechtszugehörigkeit. Zeitschift für Soziologie, Stuttgart: F. Enke Verlag Stuttgart,Jg. 18, Heft 2, S. 100-118, April 1989.

.Die soziale Konstruktion der Transsexualität. Frankfurt am Main: Suhrkamp,1993a. .Dekonstruktion und Rekonstruktion. Plädoyer für die Erforschung dês Bekannten. Feministische Studien, Weinheim: Deutschen Studien Verlag,Jg. 11, Heft 2, S. 55-67,1993b. . Die Soziale Fortpflanzung der Zweigeschlechtlichkeit. Kölner Zeitscbrift für Soziologie und Sozialpsychologie, Köln: Springer VS Springer,Jg. 46, Heft 4, S. 668-692, 1994. James, Allison; James, Adrian. Key concepts in childhood studies. London: Sage, 2008. James, Allison; Jenks, Chris; Prout, Alan. Theorizing childhood. Cambridge: Polity Press, 1998. p. 81-99. (Tradução Livre de Cleonice Maria Tomazzetti). 
.O corpo e a infância.In: KoHan, Walter Omar; Kennedy, David. Filosofia e infância: possibilidades de um encontro. 2. ed. Petrópolis: Vozes, 2000. p. 207-238.

Jordan, Ellen. Fighting boys and fantasy play: the construction of masculinity in the early years of school. Gender and Education, [S.1.]: Routledge, v. 7, n. 1, p. 69-86, 1995.

Kelle, Helga. Mädchenkultur: Jungenkultur oder eine Kultur der Zweigeschlechtlichkeit? Feministische Studien, Weinheim: Deutschen Studien Verlag,Jg. 2, S.131-142, 15 Jahrg. 1997.

. Geschleterterritorien: eine ethnographische Studie über Spiele neun-bis zwölfäriger Schulkinder. Zeitschrift für Erziehungswissenschaft, Berlin: VS Verlag, Heft 2, S. 211-228, 2 Jahrg. 1999.

. Gender and territoriality in games played by nine-to-twelve-year-old schoolchildren. Journal of Contemporary Ethnography, Londres: Sage Publications, Jg. 29, Heft 2, S. 164-197, 2000.

Kelle, Helga; Breidenstein, Georg. Geschlechteralltag in der Schulklasse: Ethnographische Studien zur Gleichaltrigenkultur. Weincheim und München: Juventa, 1998.

Kramer, Sônia. Autoria e autorização: questões éticas na pesquisa com crianças. Cadernos de Pesquisa, São Paulo: Fundação Carlos Chagas, n. 116, p. 41-59, jul. 2002.

Le Breton, David. A sociologia do corpo. Petrópolis: Vozes, 2006.

Louro, Guacira Lopes. Gênero, sexualidade e educação. Petrópolis: Vozes, 1997.

. (Org.). O corpo educado: pedagogias da sexualidade. Belo Horizonte: Autêntica, 1999. . Corpo, escola e identidade. Educação E̋ Realidade, Porto Alegre: UFRGS, v. 25, n. 2, p. 59-76, jul./dez. 2000.

. Currículo, gênero e sexualidade: O "normal", o "diferente" e o "excêntrico". In: Louro, Guacira Lopes; Neckel, Jane Felipe; Goellner, Silvana Volodre (Orgs.). Corpo, gênero e sexualidade: um debate contemporâneo. Petrópolis: Vozes, 2003. p. 41-52.

. Gênero e sexualidade: pedagogias contemporâneas. Pro-Posições, Campinas: UNICAMP, v. 19, n. 2 (56), p. 17-23, 2008a.

Um corpo estranho: ensaios sobre sexualidade e teoria queer. Belo Horizonte: Autêntica, 2008b.

McMurray, Paula. Gender behaviors in an early childhood classroom through an ethnographic lens. International Journal of Qualitative Studies in Education, [S.1.]: Routledge, v. 11, n. 2, p. 271-290, 1998.

Morrow, Virginia. Understanding gender differences in context: implications for young children's everyday lives. Children E' Society, [S.1.]: National Children's Bureau, v. 20, p. 92$-104,2006$.

PRout, Alan. Reconsiderar a nova sociologia da infância: para um estudo interdisciplinar das crianças. Ciclo de Conferências em Sociologia da Infância 2003/2004. Departamento de Ciências Sociais Aplicadas. Universidade de Stirling: Stirling, 2004. 23 p.

Rosemberg, Fúlvia. Educação sexual na escola. Cadernos de Pesquisa, São Paulo: Fundação Carlos Chagas, n. 53, p. 11-19, 1985.

. Teorias de gênero e subordinação de idade: um ensaio. Pro-Posições, Campinas:

UNICAMP, v. 7, n. 3, p. 17-23, 1996. 
. Caminhos cruzados: educação e gênero na produção acadêmica. Educação e Pesquisa, São Paulo: Universidade de São Paulo, v. 27, n. 1, p. 47-68, 2001.

SAYão, Deborah Thomé. A construção da identidade e papéis de gênero na infância: articulando temas para pensar a prática pedagógica da educação infantil. Pensar a Prática, Goiânia: Universidade Federal de Goiás, v. 5, p. 1-14, 2002.

. Pequenos homens, pequenas mulheres? Meninos e meninas? Algumas questões para pensar as relações de gênero na infância. Pró-Posições, Campinas: UNICAMP, v. 14, n. 3 (42), p. 67-87, 2003.

Relaçôes de gênero e trabalho docente na educação infantil: um estudo de professores de creche. 2005. 273 f.Tese (Doutorado em Educação) - Programa de Pós-Graduação em Educação, Universidade Federal de Santa Catarina, Florianópolis, 2005.

Schildkrout, Enid. Age and gender in Hausa society: socio-economic roles of children in urban Kano. In: La Fontaine, Jean Sybil (Ed.). Sex an age as principles of social differentiation. London: Academic Press, 1978. p. 109-137.

Scotт, Joan. Gênero: uma categoria útil de análise histórica. Educação E Realidade, Porto Alegre: UFRGS, v. 20, n. 2, p. 71-99, jul./dez. 1995.

Silva, Isabel de Oliveira e; Luz, Iza Rodrigues da. Meninos na educação infantil: o olhar das educadoras sobre a diversidade de gênero. Cadernos Pagu, Campinas: UNICAMP, v. 34, p. 17-39, 2010.

Tervooren, Tanja. Im Spielraum von Geschlecht und Begehren: Ethnographie der ausgehenden Kindheit. Weinheim und München: Juventa Verlag, 2006.

Thorne, Barrie. Gender play: girls and boys in school. Philadelphia: Open University Press Buckingham, 1993.

Walkerdine, Valerie. Sex, power and pedagogy. Screen Education, Austrália: Australian Teachers of Media, v. 38, p. 14-24, 1981.

O raciocínio em tempos pós-modernos. Educação \& Realidade, Porto Alegre: UFRGS, v. 20, n. 2, p. 207-226, 1995.

West, Candace; Zimmerman, Don H. Doing gender. Gender and Society, Londres: Sage Publications, v. 1, n. 2, p. 125-151, 1987.

\section{SOBRE A AUTORA}

Márcia Buss-Simão é doutora em educação pela Universidade Federal de Santa Catarina (UFSC). Professora da Universidade do Sul de Santa Catarina (UNISUL).

E-mail:marciabsimao@bol.com.br

Recebido em abril de 2012

Aprovado em agosto de 2012 


\section{MÁRCIA BUSS-SIMÃO}

Gênero como possibilidade ou limite da ação social: um olhar sobre a perspectiva de crianças pequenas em um contexto de educação infantil

O presente texto é parte de uma pesquisa de doutorado em que a geração de dados foi realizada no ano de 2009 em uma instituição pública de educação infantil da rede municipal de Florianópolis/SC. A fim de trazer uma descrição pela perspectiva das crianças, foram utilizados procedimentos metodológicos provenientes da etnografia, lançando mão de registros escritos, fotográficos e filmicos. $\mathrm{O}$ grupo pesquisado era composto por 15 crianças com idade entre 2 e 3 anos, sendo 12 meninas e 3 meninos. $\mathrm{Na}$ geração de dados, evidenciou-se que o pertencimento e as noções de gênero envolvem uma variedade de conhecimentos e elementos sociais e culturais, os quais requerem um estudo minucioso para se compreender como e o que as crianças sabem e aprendem sobre eles ao estabelecerem suas relações no cotidiano de uma instituição de educação infantil. Nesse sentido, tão importante como compreender o que as crianças sabem e aprendem sobre gênero, são os usos que elas dão a esse conhecimento nas relações que estabelecem com seus pares e também com os adultos e suas possibilidades de ação social.

Palavras-chave: educação infantil; gênero; ação social. 


\section{Gender as a possibility or limit of social action: a look at the perspective of young children in a context of early childhood education}

This text is a part of doctoral research conducted in a public institution of early childhood education, in Florianopolis, with a group of 12 girls and 3 boys aged two and three years. In the said research, in order to bring a description from the perspective of children, methodological procedures from ethnography were used, such as written, photographic and filmic records. In data generation, the category gender became evident as a possibility and as a limit for the social action of children. It was also evident that the belonging to and the notions of gender involve a variety of knowledge and social and cultural elements. In this sense, based on research data, it was intended to bring elements that pointed and indicated what children knew and learned about gender and the uses they made of such knowledge in the relations with their peers and with adults and their possibilities and limits of social action.

Keywords: early childhood education; gender relations; social action.

\section{Género como posibilidad o límite de acción social: una mirada hacia las perspectivas de los niños en un contexto de la educación de primera infancia}

Este texto es un extracto de una tesis doctoral en un jardin de infancia público, en Florianópolis, en un grupo de doce niñas y tres niños de entre dos y tres años. En esa investigación, con el fin de lograr una descripción desde la perspectiva de los niños, se utilizaron los procedimientos metodológicos de la etnografía como registros escritos, fotográficos y fílmicos. La generación de los datos reveló la categoría de género como una posibilidad o como un límite para los niños de acción social, al mismo tiempo, se hizo evidente que las nociones de pertenencia y de género implican una variedad de conocimientos y elementos sociales y culturales. Por lo tanto, con base en los datos del estudio, la intención era traer elementos que demostrasen $e$ indicasen lo que los niños sabian y habian aprendido sobre el género y qué usos le daban a esos conocimientos en las relaciones que establecen con sus pares y con adultos, y sus limites y posibilidades para la acción social.

Palabras clave: educación infantil; relaciones de género; acción social. 